\title{
The influence of hydrostatic pressure on phase transition in ferroelectrics of displacement type
}

\author{
A.G.Slivka \\ Department of Physics, Uzhgorod State University, \\ 32 Voloshin Str., 294000 Uzhgorod, Ukraine \\ Received November 1, 1999

\begin{abstract}
Within the phenomenological theory of phase transitions the temperature change in electrostriction coefficients has been shown to lead to CurieWeiss constant pressure dependence, non-linearity of phase $p, T$-diagram and change in phase transition character in ferroelectrics of displacement type.
\end{abstract}

Key words: ferroelectrics, phase transitions, pressure

PACS: $77.80 . B h, 64.60 . F r$

As it is known, in ferroelectrics of displacement type the order of magnitude of Curie-Weiss constant $C_{\mathrm{w}}$ is $\sim 10^{5} \mathrm{~K}$ and the decrease in phase transition temperature $(\mathrm{PT})$ under the action of external hydrostatic pressure is typical for it. In some works $[1,2]$ within the phenomenological theory, the change in temperature and character of PT in ferroelectrics of displacement type at an all-sided compressibility has qualitatively been explained. However, at quantitative calculations of tricritical point coordinates and pressure coefficients of shift of PT temperatures for specific ferroelectric crystals, there takes place an essential discrepancy with experimental results [3-6]. It should be mentioned that the authors of these works do not pay attention to the experimentally known fact - Curie-Weiss constant pressure dependence. This dependence is experimentally established for practically all the known ferroelectrics [7] and bears an anomalous character in the vicinity of polycritical points in the constitution diagrams.

In the given work at a phenomenological level the attempt is made to find out the cause of $C_{\mathrm{w}}(p)$ dependence and to consider all probable cases of the change in $\mathrm{PT}$ temperature in ferroelectrics of displacement type under the action of external hydrostatic pressure.

Let us consider an isotropic model of a crystal with the second-order PT. Following the work [2] the density of thermodynamic potential for proper uniaxial 
ferroelectric will be given in the following form

$$
\Phi_{1}=\Phi_{0}+\frac{\alpha}{2} P_{\mathrm{s}}^{2}+\frac{\beta}{4} P_{\mathrm{s}}^{4}+\frac{\gamma}{6} P_{\mathrm{s}}^{6}+\ldots .
$$

Let's add an elastic part to it in the form of

$$
\Phi_{\mathrm{el}}=\frac{1}{2} c u^{2}+g u P_{\mathrm{s}}^{2}+\frac{1}{2} h u^{2} P_{\mathrm{s}}^{2}-u p,
$$

in which $p$ is the hydrostatic pressure, $c$ is the tensor of elastic modulus, $u$ is the tensor of deformations, $g$ is an electrostriction coefficient, $h$ is a quadratic electrostriction coefficient. Taking into consideration the condition of the thermodynamic potential minimum $\Phi=\Phi_{1}+\Phi_{\mathrm{el}}$, that is $\partial \Phi / \partial u=0$, we find

$$
u \cong \frac{1}{c}\left[p-\left(g+\frac{h}{c} p\right) P_{\mathrm{s}}^{2}+\frac{g h}{c} P_{\mathrm{s}}^{4}\right] .
$$

The substitution of the relationship obtained into (2) with the account of (1) gives the following expression for the thermodynamic potential

$$
\Phi=\Phi_{0}+\frac{\tilde{\alpha}}{2} P_{\mathrm{s}}^{2}+\frac{\tilde{\beta}}{4} P_{\mathrm{s}}^{4}+\frac{\tilde{\gamma}}{6} P_{\mathrm{s}}^{6}+\ldots+\frac{1}{2 c} p^{2},
$$

where overnormalized coefficients are dependent on $p$

$$
\frac{\tilde{\alpha}}{2}=\frac{\alpha}{2}+\frac{g}{c} p+\frac{h}{2 c^{2}} p^{2} ; \quad \frac{\tilde{\beta}}{4}=\frac{\beta}{4}-\frac{g^{2}}{2 c}-\frac{g h}{c^{2}} p ; \quad \frac{\tilde{\gamma}}{6}=\frac{\gamma}{6}+\frac{g h^{2}}{2 c^{2}} .
$$

In the work [1,2] the magnitudes $g$ and $h$ are taken as independent of temperature and pressure, and $\alpha=\alpha_{0}\left(T-T_{0}\right)$, where $\alpha_{0}=1 /\left(\varepsilon_{b} C_{\mathrm{w} 0}\right)$. The magnitudes $T_{0}$ and $C_{\mathrm{w} 0}$ are respectively, the temperature and Curie-Weiss constant under the atmospheric pressure. In this case $\tilde{\beta}$ is dependent on $p$ only if $\tilde{\alpha}$ non-linearly depends on $p$ (that is $h \neq 0$ ). Taking into account that experimental dependences $\varepsilon^{-1}(p) \cong \tilde{\alpha}(p)$ for ferroelectrics of displacement type have a linear character [3-6] it becomes doubtful how $\tilde{\beta}$ coefficient may change with the pressure at $h=0$. Secondly, $\alpha_{0}$ as well as $C_{\mathrm{w} 0}$ are independent of the pressure. These two consequences from the analysis of relationships (5) contradict the experimental results and do not require quantitative estimates.

Let us consider the case when electrostriction coefficients $g$ and $h$ depend on the temperature. In the linear approximation we shall present these dependences as $g=g_{0}\left[1+G\left(T-T_{0}\right)\right]$ and $h=h_{0}\left[1+H\left(T-T_{0}\right)\right]$. Then

$$
\tilde{\alpha}=\alpha_{0 T}\left(T-T_{0}\right)+\frac{2 g_{0}}{c} p+\frac{h_{0}}{c^{2}} p^{2},
$$

where $\alpha_{0 T}=\left[\alpha_{0}+\frac{2 G g_{0}}{c} p+\frac{H h_{0}}{c^{2}} p^{2}\right]$. So, temperature dependences $g(T)$ and $h(T)$ cause the dependence of pressure of $\alpha 0 T$ coefficient as well as the Curie-Weiss constant $C_{\mathrm{w}}=\left(\varepsilon_{b} \alpha_{0 T}\right)^{-1}$. In general case this dependence may have a non-linear character. To simplify the further analysis the dependence $\alpha_{0 T}(p)$ may be given in the form

$$
\alpha_{0 T}(p)=\left[\varepsilon_{b} C_{\mathrm{w}}(p)\right]^{-1}=\left[\varepsilon_{b} C_{\mathrm{w} 0}\left(1+f p+z p^{2}\right)\right]^{-1} .
$$



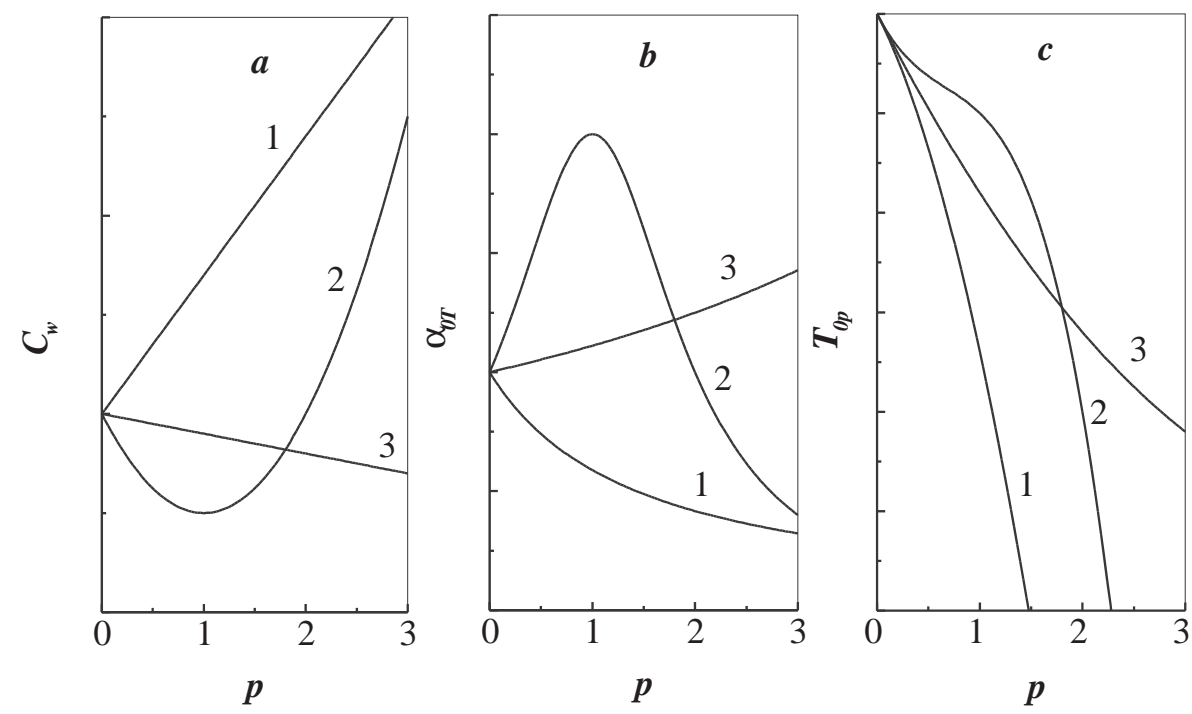

Figure 1. Pressure dependences of Curie-Weiss constant $C_{\mathrm{w}}$, coefficient $\alpha_{0 T}$ and $T_{0 p}$ PT temperature of a ferroelectric for cases: $1-f>0, z=0 ; 2-f<0$, $z>0 ; 3-f<0, z=0$.

Such a choice is conditioned by the fact that $C_{\mathrm{w}}(p)$ dependence for the majority of the known ferroelectrics of displacement type is experimentally established, in contrast to dependences $g(T)$ and $h(T)$. That is why coefficients

$$
f=\frac{1}{C_{\mathrm{w} 0}} \frac{\partial C_{\mathrm{w}}}{\partial p}, \quad z=\frac{1}{C_{\mathrm{w} 0}} \frac{\partial^{2} C_{\mathrm{w}}}{\partial p^{2}}
$$

may be numerically defined for a specific crystal from the experiment.

In figure 1a three variants of $C_{\mathrm{w}}(p)$ dependence are given in relative units, which agree well with the experiment. The first case is typical for $\mathrm{Sn}_{2} \mathrm{P}_{2} \mathrm{Se}_{6}$ incommensurate ferroelectric, the second - for $\mathrm{Sn}_{2} \mathrm{P}_{2} \mathrm{~S}_{6}$ and SbSJ, the third - for ferroelectrics of perovskite type $\left(\mathrm{BaTiO}_{3}, \mathrm{SrTiO}_{3}, \mathrm{PbTiO}_{3}\right)$ [7]. In figure $1 \mathrm{~b}$ the corresponding pressure dependences of $\alpha_{0 T}$ coefficient for these cases are given. Under the condition such that $\tilde{\alpha}(p, T)=0$ and taking into consideration (6) the pressure dependence of PT temperature $\left(T_{0 p}\right)$ may be written in the following form

$$
\begin{aligned}
T_{0 p} \cong & T_{0}-\frac{2 g_{0} \varepsilon_{b} C_{\mathrm{w} 0}}{c} p-\left(\frac{2 g_{0} \varepsilon_{b} C_{\mathrm{w} 0}}{c} f+\frac{h_{0} \varepsilon_{b} C_{\mathrm{w} 0}}{c^{2}}\right) p^{2} \\
& -\left(\frac{2 g_{0} \varepsilon_{b} C_{\mathrm{w} 0}}{c} z+\frac{h_{0} \varepsilon_{b} C_{\mathrm{w} 0}}{c^{2}} f\right) p^{3} .
\end{aligned}
$$

The $T_{0 p}$ dependences calculated in accordance with (8) are given in figure 1c. As we see for all the three variants considered, there occurs a non-linear behaviour with the pressure of PT temperature $T_{0 p}$. For the second case at the value of pressure that is assigned to extremuma in dependences $C_{\mathrm{w}}(p)$ and $\alpha_{0 T}(p)$ the inflection $\left(\partial^{2} T_{0 p} / \partial p^{2}\right)=0$ depending on $T_{0 p}(p)$ is observed. Taking into account that experimentally established [3-6] $p, T$-diagrams of ferroelectrics (except for SbSJ) have 
a linear character, it was of interest to estimate the value of non-linear pressure coefficient of PT temperature shift $\left(\partial^{2} T_{0 p} / \partial p^{2}\right)$ for different ferroelectrics.

In accordance with these relationships using the results of works [3-6] the values of linear and quadratic PT shift temperature coefficients for different ferroelectrics are calculated. They, respectively, make up for $\mathrm{BaTiO}_{3}$ : $-48 \mathrm{~K} / \mathrm{GPa}$ and $+4,2 \mathrm{~K} / \mathrm{GPa}^{2}$; for $\mathrm{SrTiO}_{3}$ : $-17 \mathrm{~K} / \mathrm{GPa}$ and $+3,4 \mathrm{~K} / \mathrm{GPa}^{2}$; for $\mathrm{PbTiO}_{3}$ : $-71 \mathrm{~K} / \mathrm{GPa}$ and $+16 \mathrm{~K} / \mathrm{GPa}^{2}$, for $\mathrm{Sn}_{2} \mathrm{P}_{2} \mathrm{Se}_{6}$ : $-178 \mathrm{~K} / \mathrm{GPa}$ and $-160 \mathrm{~K} / \mathrm{GPa}^{2}$, for $\mathrm{Sn}_{2} \mathrm{P}_{2} \mathrm{~S}_{6}$ : $-221 \mathrm{~K} / \mathrm{GPa}$ and $+139 \mathrm{~K} / \mathrm{GPa}^{2}$; for SbSJ: $-371 \mathrm{~K} / \mathrm{GPa}$ and $+727 \mathrm{~K} / \mathrm{GPa}^{2}$. The values of $\left(\partial T_{0 p} / \partial p\right)$ coefficient obtained for different crystals agree well with the results of direct experimental measurements [3-6]. The value of $\left(\partial^{2} T_{0 p} / \partial p^{2}\right)$ coefficient for all crystals except SbSJ are within the error of the experimental determination. That is why their phase diagrams have a linear character being experimentally determined. For SbSJ ferroelectric at pressure of $500 \mathrm{MPa}$ the quadratic PT temperature shift in accordance with the given calculations makes up about $180 \mathrm{~K}$, that agrees with the results of the works [5].

Thus, the analysis carried out indicates that within the phenomenological theory of PT, the dependence $C_{\mathrm{w}}$ of pressure may be explained by the temperature change in electrostriction coefficients of a crystal along its phase $p, T$-diagram. Secondly, the change in $C_{\mathrm{w}}$ with the pressure testifies to a non-linear character of baric dependence of PT temperature. Thirdly, linear and baric coefficients of PT shift temperature may be calculated from the results of investigations conducted regarding the dependence of $C_{\mathrm{w}}(p)$. Fourthly, as it was shown earlier in work [7], the temperature change in electrostriction coefficients of a crystal also causes the change in $\tilde{\beta}$ coefficient along its phase $p, T$-diagram and is responsible for the appearance of polycritical points.

\section{References}

1. Benguigui L. Change of order of a phase transition by the influence of an external parameter. // Phys. Stat. Sol. B, 1973, vol. 60, p. 835-841.

2. Kosin P., Ord T. Change of the order of ferroelectric phase transition under hydrostatic pressure. // Proc. Est. Ac. Sci. Phys. Math., 1989, vol. 38, No. 4, p. 457-459.

3. Samara G. Pressure and temperature dependences of the dielectric properties of the perovskites $\mathrm{BaTiO}_{3}$ and $\mathrm{SrTiO}_{3}$. // Phys. Rev., 1966, vol. 151, No. 2, p. 378-386.

4. Ramirez R., Lapena M., Gonzalo J. Pressure dependence of free-energy expansion coefficients in $\mathrm{PbTiO}_{3}$ and $\mathrm{BaTiO}_{3}$ and tricritical point behaviour. // Phys. Rev. B, 1990, vol. 42, No. 4, p. 2604-2606.

5. Gerzanich E., Fridkin V. Ferroelectrics of the $A^{V} B^{V I} C^{V I I}$ group. Moscow, Nauka, 1982 (in Russian).

6. Slivka A., Gerzanich E., Guranich P., Shusta V., Kedyulich V. Pressure behaviour of Curie-Weiss constant in $\mathrm{Sn}_{2} \mathrm{P}_{2}\left(\mathrm{~S}_{1-x} \mathrm{Se}_{x}\right)$ ferroelectric solid solutions. // Ukr. J. Phys., 1997, vol. 42, No. 2, p. 211-215. (in Ukrainian).

7. Slivka A. Pressure behaviour of Curie-Weiss constant in displacement type ferroelectrics. // Reports of Uzhgorod University, Series Physics, 1998, No. 3, p. 94-98 (in Ukrainian). 


\section{Вплив гідростатичного тиску на фазовий перехід у сегнетоелектриках типу зміщення}

\section{О.Г.Сливка}

Фізичний факультет, Ужгородський держуніверситет, 294000 Ужгород, вул. А.Волошина, 32

Отримано 1 листопада 1999 р.

В рамках феноменологічної теорії фазових переходів показано, що температурна зміна електрострикційних коефіцієнтів приводить до залежності константи Кюрі-Вейсса від тиску, нелінійності фазової $p, T$-діаграми та зміни характеру ФП у сегнетоелектрику типу зміщення.

Ключові слова: сегнетоелектрики, фазові переходи, гідростатичний тиск

PACS: $77.80 . \mathrm{Bh}, 64.60 . \mathrm{Fr}$ 
